\title{
Article \\ Surface Modification of Commercial Cotton Yarn as Electrode for Construction of Flexible Fiber-Shaped Supercapacitor
}

\author{
Wei Xiao *D, Jing Huang, Wenjie Zhou, Qinglin Jiang, Ying Deng *, Yanhua Zhang * and Liangliang Tian \\ Research Institute for New Materials Technology, Chongqing University of Arts and Sciences, Yongchuan, \\ Chongqing 402160, China; HJngabc@163.com (J.H.); wenjie_zhou@aliyun.com (W.Z.); \\ jiang19990913@126.com (Q.J.); tianl107@163.com (L.T.) \\ * Correspondence: showame@aliyun.com (W.X.); dengying.163@163.com (Y.D.); zyhcoco@163.com (Y.Z.); \\ Tel.: +86-23-4989-1752 (W.X.)
}

Citation: Xiao, W.; Huang, J.; Zhou, W.; Jiang, Q.; Deng, Y.; Zhang, Y.;

Tian, L. Surface Modification of Commercial Cotton Yarn as Electrode for Construction of Flexible Fiber-Shaped Supercapacitor. Coatings 2021, 11, 1086. https:// doi.org/10.3390/coatings11091086

Academic Editor: Mulugeta Wayu

Received: 8 August 2021

Accepted: 5 September 2021

Published: 8 September 2021

Publisher's Note: MDPI stays neutral with regard to jurisdictional claims in published maps and institutional affiliations.

Copyright: (C) 2021 by the authors. Licensee MDPI, Basel, Switzerland. This article is an open access article distributed under the terms and conditions of the Creative Commons Attribution (CC BY) license (https:/ / creativecommons.org/licenses/by/ $4.0 /)$.

\begin{abstract}
In this study, we report on the rational design and facile preparation of a cotton-reduced graphene oxide-silver nanoparticle (cotton-RGO-AgNP) hybrid fiber as an electrode for the building of a flexible fiber-shaped supercapacitor (FSSC). It was adequately characterized and found to possess a well-defined core-shell structure with cotton yarn as a core and a porous RGO-AgNP coating as a shell. Thanks to the unique morphological features and low electrical resistance (only $2.3 \Omega \cdot \mathrm{cm}^{-1}$ ), it displayed attractive supercapacitive properties. When evaluated in a three-electrode setup, this FSSC electrode delivered the highest linear and volumetric specific capacitance of up to ca. $12.09 \mathrm{mF} \cdot \mathrm{cm}^{-1}$ and ca. $9.67 \mathrm{~F} \cdot \mathrm{cm}^{-3}$ with a satisfactory rate capability as well as a decent cycling stability. On the other hand, an individual parallel symmetric FSSC cell constructed by this composite fiber fulfilled the largest linear and volumetric specific capacitance of ca. $1.67 \mathrm{mF} \cdot \mathrm{cm}^{-1}$ and ca. $0.67 \mathrm{~F} \cdot \mathrm{cm}^{-3}$ and offered the maximum energy density, as high as ca. $93.1 \mu \mathrm{Wh} \cdot \mathrm{cm}^{-3}$, which outperformed a great number of graphene- and textile yarn-based FSSCs. Impressively, bending deformation brought about quite a limited effect on its electrochemical behaviors and almost no capacitance degradation took place during the consecutive charge/discharge test for over 10,000 cycles. Consequently, these remarkable performances suggest that the currently developed cotton-RGO-AgNP fiber has considerable application potential in flexible, portable and wearable electronics.
\end{abstract}

Keywords: cotton; textile yarn; graphene; silver nanoparticles; surface modification; flexible fiber-shaped supercapacitor

\section{Introduction}

Flexible electronics have aroused ongoing attention in both academic and industrial communities due to the huge application background in a broad range of areas such as smart garments, implantable devices, wireless sensors, and so on [1-3]. Undoubtedly, powering this novel equipment calls for advanced power modules with some crucial features, including light weight, high flexibility, good mechanical strength and prominent electrochemical behaviors [1-3]. Amongst different sorts of energy-storage devices, onedimensional (1D), flexible, fiber-shaped supercapacitors (FSSCs) have been regarded as promising candidates for satisfying the corresponding requirements. Because they benefit from small volume, tiny size and advantageous flexibility, they can be easily made into a variety of shapes and integrated into diverse miniature devices [1-3]. Lots of FSSCs have been developed recently and their electrodes are fabricated mainly based on two strategies. One is to deposit or grow electroactive substances onto conductive fiber-shaped current collectors, such as metal wires and carbon fibers, to endow the resulting electrodes with electrochemical properties [4-8]. The other is to synthesize graphene-, carbon nanotubeand conductive polymer-based fibers, which not only possess electrical conductivity but also have charge storage abilities [9-13]. However, both of these two popular methodolo- 
gies often need sophisticated instruments and suffer from high cost, time consumption and complicated fabrication processes, which severely block the practical use on a large scale.

Textile yarns (e.g., commercial cotton yarns) are inexpensive, comfortable, highly flexible and sufficiently robust. More importantly, they can be readily woven into fabrics. These unique characteristics make them quite suitable for the development of FSSCs. Unfortunately, it is impossible to directly use pristine textile yarns as electrodes due to their intrinsic insulation and electrochemical inertness. To overcome the drawbacks, many efforts were made in previous work [14-21]. For example, a cotton/ $\mathrm{Au} / \mathrm{CoNi}_{2} \mathrm{~S}_{4}$ hybrid yarn electrode was prepared by the chemical modification of cotton yarn with 3-aminopropyltrimethoxysilane, followed by the adsorption of $\mathrm{Au}$ nanoparticles and the electrochemical deposition of $\mathrm{CoNi}_{2} \mathrm{~S}_{4}$ nanosheets [14]. Similarly, the metallization of cotton thread with nickel nanoparticles via electroless plating and further hydrothermal growth of $\mathrm{Co}-\mathrm{Ni}$ layered double hydroxide (Co-Ni LDH) nanosheets give rise to the production of cotton/Ni/Co-Ni LDH fiber electrodes [15]. In some other studies, cotton/graphene/polyaniline and cotton/CNT/polypyrrole yarn electrodes were also reported, which were obtained by the coating of cotton yarns with graphene and carbon nanotubes (CNTs) coupled with the subsequent polymerization of aniline and pyrrole, respectively $[16,17]$. It is therefore the case that functionalizing textile yarns with nanostructured guest species through rational design and appropriate surface decoration is indeed a feasible and effective way to impart them with good electrical conductivity and electrochemical performances.

Motivated by this strategy, in the present work, we report a cotton-reduced graphene oxide-silver nanoparticle (cotton-RGO-AgNP) composite fiber by coating common cotton yarns with graphene oxide (GO) sheets, followed by the electrostatic adsorption of silver ammonium and the subsequent hydrazine vapor-involved chemical reduction process (Figure 1). Differing from the above-mentioned reports, such fabrication is sufficiently facile and not dependent on sophisticated instruments. More importantly, due to the unique core-shell-structured morphology and splendid conductivity, the as-prepared cotton-RGOAgNP fiber can be directly used as an FSSC electrode, and it showed impressive capacitive behaviors in both three- and two-electrode systems. A parallel symmetric FSSC device was also constructed based on the cotton-RGO-AgNP hybrid fiber, which not only possessed prominent charge storage capabilities, but also exhibited stable electrochemical properties under various bending states. By virtue of the convenient preparative method and remarkable electrochemical performances, the currently designed textile yarn electrode would be a prospective candidate for utilization in the new generation of flexible electronics.

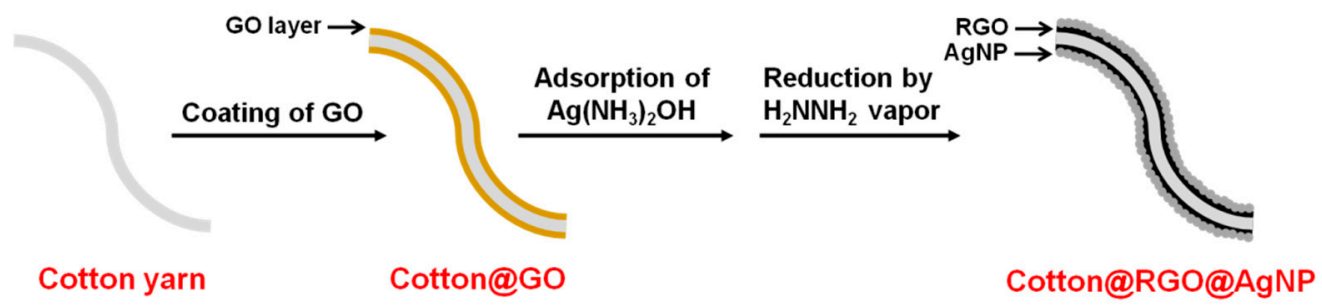

Figure 1. Schematic illustration of the synthetic process of cotton-RGO-AgNP hybrid fiber.

\section{Materials and Methods}

\subsection{Chemicals}

Cotton thread was purchased from the local market. Aqueous dispersion of GO sheets $\left(10 \mathrm{mg} \cdot \mathrm{mL}^{-1}\right)$, GO powder, reduced graphene oxide (RGO) powder and pure silver nanoparticles were provided by Beijing Beike 2D Materials Co., Ltd. (Beijing, China). $\mathrm{KOH}$, $\mathrm{AgNO}_{3}$, hydrazine (80 wt.\%), polyvinyl alcohol (PVA) and polyethylene terephthalate (PET) film were bought from Aladdin Reagent Co., Ltd. (Shanghai, China). Ultra-pure water was produced from a Milli-Q machine and used throughout. 


\subsection{Synthesis of Cotton-RGO-AgNP Hybrid Fiber}

A length of cotton yarn of $\sim 12 \mathrm{~cm}$ was placed in gentle tension and a GO suspension of $10 \mathrm{mg} \cdot \mathrm{mL}^{-1}$ was brushed onto its surface, which was then dried in an oven. This brushing-drying process was repeated 5 times to ensure a uniform and complete coating of GO on the surface of the cotton yarn. Thereafter, the GO-wrapped cotton yarn was immersed in a solution of silver-ammonia complex $(100 \mathrm{mM})$ for $30 \mathrm{~min}$ to sufficiently adsorb $\left[\mathrm{Ag}\left(\mathrm{NH}_{3}\right)_{2}\right]^{+}$via coordinative and electrostatic interaction, followed by rinsing with abundant water. Successively, the surface-decorated moist cotton yarn was transferred into a vessel of $1 \mathrm{~L}$ capacity, within which $30 \mu \mathrm{L}$ of hydrazine $(80 \mathrm{wt} . \%)$ was added beforehand. The vessel was tightly sealed and subjected to heating at $90{ }^{\circ} \mathrm{C}$ for $8 \mathrm{~h}$. During this process, the coated GO and adsorbed silver-ammonia complex were reduced to RGO and AgNPs, respectively, leading to the final product of cotton-RGO-AgNP composite fiber. As a contrastive specimen, cotton-RGO fiber was also prepared according to the above procedure but without the introduction of the silver-ammonia complex.

\subsection{Content Determinations of Each Chemical Composition within Cotton-RGO-AgNP Fiber}

First, the weight percentage of cotton within cotton-RGO-AgNP fiber was acquired according to the weight of the pristine cotton yarn and to that after the surface decoration. To further exactly ascertain the contents of the other two components loaded in the final product, $60 \mathrm{mg}$ of cotton-RGO-AgNP fiber was put into $100 \mathrm{~mL}$ of diluted nitric acid overnight to fully dissolve the AgNPs. After that, the reaction solution was filtered and diluted and the concentration of $\mathrm{Ag}^{+}$was determined by inductively coupled plasma (ICP) analysis. Therefore, the content of AgNPs within cotton-RGO-AgNP could be readily deduced based on the $\mathrm{Ag}^{+}$concentration and the usage amount of the sample. Consequently, its RGO content can be found out via simple calculation as well.

\subsection{Fabrication of Parallel Symmetric FSSC Device}

Three grams of PVA was thoroughly dissolved in $26 \mathrm{~mL}$ of ultra-pure water under vigorous stirring and heating in a water bath at $90{ }^{\circ} \mathrm{C}$. Three point four grams of $\mathrm{KOH}$ dissolved in $4 \mathrm{~mL}$ of ultra-pure water was slowly added into the mixture, which was thereafter sonicated for a while to remove the bubbles, yielding a transparent gel electrolyte. To assemble a symmetric FSSC device, two identical cotton-RGO-AgNP fiber electrodes ( $3 \mathrm{~cm}$ in length) were placed in parallel on a PET film with the spacing distance less than $0.5 \mathrm{~mm}$, and then $\sim 200 \mu \mathrm{L}$ of PVA/KOH gel electrolyte was dropped onto the electrodes, covered by another PET film and allowed to dry naturally at room temperature.

\subsection{Characterizations}

X-ray diffraction patterns (XRD, Tongda TD-3500 diffractometer, $\mathrm{CuK} \alpha$ radiation source, Dandong Tongda Science\&Tecnology Co. Ltd., Dandong, China), X-ray photoelectron spectra (XPS, PHI 5000 Versa Probe apparatus, ULVAC-PHI Inc., Chigasaki, Japan), Raman spectra (Bruker RFS-100 spectrometer, an exciting laser of $514 \mathrm{~nm}$, Bruker Co. Ltd., Karlsruhe, Germany) and ICP (Thermo iCAP 7000 instrument, Thermo Fisher Scientific Inc., Waltham, MA, USA) analyses were implemented to study the chemical constituents and structural information of synthesized materials. Scanning electron microscope (SEM, Zeiss Gemini SEM 300, Carl Zeiss Co. Ltd., Oberkochen, Germany) observations were performed to gain insight into the morphological details of the synthesized materials.

\subsection{Electrochemical Assessments}

The supercapacitive behaviors of the fiber electrode and the corresponding FSSC device were investigated on a CHI760E electrochemical workstation by adopting three methods, including cyclic voltammetry (CV), galvanostatic charge/discharge (GCD) and electrochemical impedance spectra (EIS). For the tests in the three-electrode setup, the experiments were conducted in $2 \mathrm{M} \mathrm{KOH}$ with a fiber electrode ( $3 \mathrm{~cm}$ in length), an $\mathrm{Hg} / \mathrm{HgO}$ electrode and platinum foil as working, reference and counter electrodes, respectively. 
The specific capacitance of the fiber electrode is deduced on a basis of the following two equations and GCD tests:

$$
\begin{gathered}
C_{\mathrm{L}}=\mathrm{It} / \mathrm{L} \Delta \mathrm{V} \\
\mathrm{C}_{\mathrm{V}}=\mathrm{C}_{\mathrm{L}} / 250 \pi \mathrm{d}^{2}
\end{gathered}
$$

$\mathrm{C}_{\mathrm{L}}, \mathrm{I}, \mathrm{t}, \mathrm{L}, \Delta \mathrm{V}, \mathrm{C}_{\mathrm{V}}$ and $\mathrm{d}$ are linear capacitance $\left(\mathrm{mF} \cdot \mathrm{cm}^{-1}\right)$, discharge current $(\mathrm{mA})$, discharge time $(\mathrm{s})$, length of fiber electrode $(\mathrm{cm})$, potential range $(\mathrm{V})$, volumetric capacitance $\left(\mathrm{F} \cdot \mathrm{cm}^{-3}\right)$ and diameter of fiber electrode $(\mathrm{cm})$, respectively. In addition, the capacitive properties of the symmetric FSSC device made from cotton-RGO-AgNP fiber were evaluated by employing a two-electrode configuration, whose main performance parameters were calculated in accordance with the following four formulas as well as with GCD tests:

$$
\begin{gathered}
\mathrm{C}_{\mathrm{L}, \text { FSSC }}=\mathrm{It}_{\mathrm{t}} \mathrm{L}_{\mathrm{FSSC}} \Delta \mathrm{V}_{\mathrm{FSSC}} \\
\mathrm{C}_{\mathrm{V}, \text { FSSC }}=\mathrm{C}_{\mathrm{L}, \text { FSSC }} / 500 \pi \mathrm{d}^{2} \\
\mathrm{E}_{\mathrm{V}}=\left(\mathrm{C}_{\mathrm{V}, \text { FSSC }} \Delta \mathrm{V}_{\mathrm{FSSC}}^{2}\right) / 7.2 \\
\mathrm{P}_{\mathrm{V}}=3600 \mathrm{E}_{\mathrm{V}} / \mathrm{t}
\end{gathered}
$$

$\mathrm{C}_{\mathrm{L}}$, FSSC, $\mathrm{C}_{\mathrm{V}}$, FSSC, $\mathrm{E}_{\mathrm{V}}$ and $\mathrm{P}_{\mathrm{V}}$ are associated with the linear capacitance $\left(\mathrm{mF} \cdot \mathrm{cm}^{-1}\right)$, volumetric capacitance $\left(\mathrm{F} \cdot \mathrm{cm}^{-3}\right)$, volumetric energy density $\left(\mathrm{mWh} \cdot \mathrm{cm}^{-3}\right)$ and volumetric power density $\left(\mu \mathrm{W} \cdot \mathrm{cm}^{-3}\right)$ of an individual FSSC cell, respectively. I, t, $\mathrm{L}_{\mathrm{FSSC}}, \Delta \mathrm{V}_{\mathrm{FSSC}}$ and $\mathrm{d}$ represent discharge current $(\mathrm{mA})$, discharge time (s), length of FSSC cell $(\mathrm{cm})$, output voltage of a single FSSC cell $(\mathrm{V})$ and diameter of fiber electrode $(\mathrm{cm})$, respectively.

\section{Results and Discussion}

\subsection{Materials Characterizations}

XRD characterizations were first implemented to find out the crystal textures of corresponding materials. Commercial pristine cotton yarn consists of polymer chains of cellulose, which is arranged into a certain crystalline phase, thus rendering XRD peaks centered at $14.8^{\circ}, 16.7^{\circ}, 22.9^{\circ}$ and $34.3^{\circ}$ (black curve in Figure 2) [22,23]. These four peaks can also be recognized in the XRD pattern of cotton-RGO-AgNP composite fiber (green curve). In addition, five more sharp diffraction peaks appear at $38.2^{\circ}, 44.3^{\circ}, 64.5^{\circ}, 77.5^{\circ}$ and $81.5^{\circ}$ in this pattern, perfectly coinciding with the XRD peaks of elemental silver nanoparticles (blue curve), which belong to the crystallographic planes of (111), (200), (220), (311) and (222) for face-centered cubic silver (JCPDS: 65-2871), respectively [23,24]. It is well known that RGO has a typical peak at $\sim 24^{\circ}$ and there is indeed a wide and weak XRD peak at $23.5^{\circ}$ for the purchased RGO powder (red curve) [24,25]. However, such a peak is absent in the XRD pattern of cotton-RGO-AgNP fiber and therefore it is likely that it is overlapped by the dominant peak originating from the cotton constituent $[25,26]$.

Figure 3a exhibits an optical photograph of a length of pristine cotton thread, showing white in color. Figure $3 b-e$ are a set of its SEM images, revealing that cotton yarn is actually composed of lots of microsized cotton fiber bundles, which are twisted and intertwined together. After surface modification, the as-prepared cotton-RGO-AgNP fiber turns bright silver-gray but maintains excellent flexibility (Figure 3f,g). Its structural and morphological details were also examined by SEM observations. As can be seen in the top-view images (Figure $3 \mathrm{~h}-\mathrm{k}$ ), numerous AgNPs are stacked and united to form a continuous and rough silver film uniformly coated on the external surface. Figure 31-o are cross-sectional SEM images of the same sample exhibited in Figure $3 \mathrm{~h}-\mathrm{k}$. As expected, the cotton-RGO-AgNP fiber possesses a characteristic core-shell structure (Figure 31,m). Namely, it consists of a cotton yarn core with the diameter of $\sim 200 \mu \mathrm{m}$ and a porous RGO-AgNP hybrid film shell with the thickness of $100 \mu \mathrm{m}$. Notably, AgNPs are not only well distributed throughout the outer surface but are also abundantly embedded in the inner part of the shell (Figure 3n,o), which act as spacers to effectively circumvent serious aggregation of RGO during the fabrication processes. Benefiting from the unique 
morphology and intrinsic conductive nature of the RGO and AgNP components, the synthesized cotton-RGO-AgNP has high conductivity with an electrical resistance of only $2.3 \Omega \cdot \mathrm{cm}^{-1}$ (inset of Figure $3 \mathrm{f}$ ). Such resistance is much lower than that of lots of recently reported textile thread-, carbon- and graphene-based FSSC electrodes, whose resistance is always beyond $10 \Omega \cdot \mathrm{cm}^{-1}[17,20,27-29]$. It is assumed that the exceptional conductivity and distinct porous structure would accelerate the transportation of electrons and facilitate the penetration, diffusion and adsorption of electrolyte ions during the charge/discharge processes, hence upgrading the charge storage abilities of the currently developed FSSC electrode and device. Moreover, via the appropriate measurements and calculations described in the experimental section, the chemical composition content of cotton-RGOAgNP fiber can be ascertained, which is 30.9 wt.\% for cotton, 32.7 wt. $\%$ for RGO and 36.4 wt. \% for AgNPs.

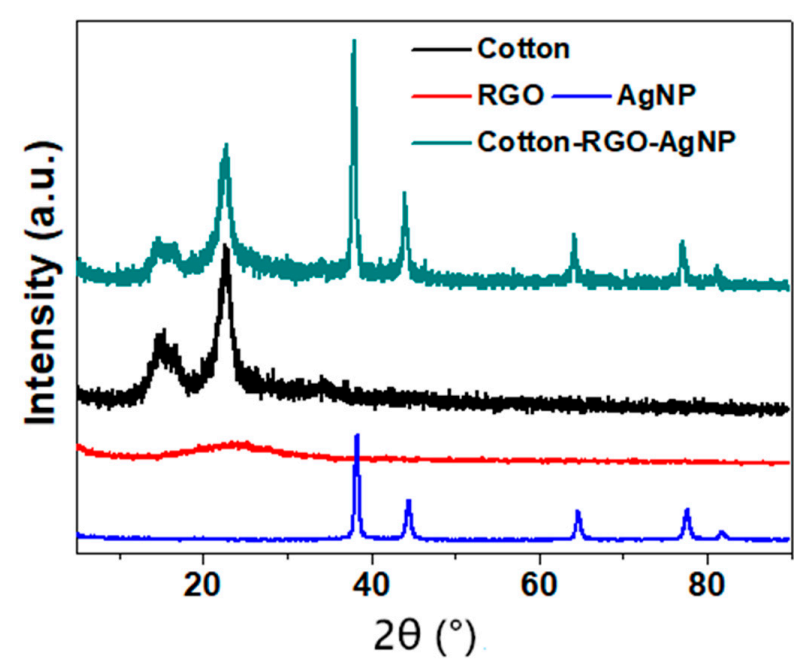

Figure 2. XRD patterns of commercially available cotton thread, RGO powder and AgNPs together with that of the cotton-RGO-AgNP hybrid fiber synthesized in the present work.

Figure 4a presents the Raman spectra of GO powder and cotton-RGO-AgNP fiber, both of which give two typical bands centered around 1350 and $1610 \mathrm{~cm}^{-1}$. As documented in previously published literature, they should correspond to the D and G bands of carbon materials, respectively $[9,10,24,30]$. The former is usually relevant to the defects and disruption of the crystalline region, while the latter refers to the $\mathrm{sp}^{2}$-type carbon atom network $[9,10,30]$. The intensity ratio of the $\mathrm{D}$ to $\mathrm{G}$ band (denoted as $I_{\mathrm{D}} / I_{\mathrm{G}}$ thereafter) is extensively employed to judge the disorder level in graphitic materials $[9,10,30]$. The $I_{\mathrm{D}} / I_{\mathrm{G}}$ value of cotton-RGO-AgNP fiber is $\sim 1.15$, which is evidently higher than that of GO powder ( 0.95), demonstrating the abundant elimination of oxygen-rich groups during the hydrazine-involved reductive reaction $[10,12,30]$. That is, the GO component coated on cotton yarn was sufficiently reduced to RGO and hybridized in the final product. High-resolution XPS characterizations further validate the same result. As exhibited in Figure 4b,c, both of the measured XPS C1s spectra of GO powder and cottonRGO-AgNP fiber can be fitted into three well-defined peaks, which are attributable to $\mathrm{C}=\mathrm{C} / \mathrm{C}-\mathrm{C} / \mathrm{C}-\mathrm{H}$ bonding at $284.7 \mathrm{eV}, \mathrm{C}-\mathrm{OH}$ bonding at $286.7 \mathrm{eV}$ and $\mathrm{C}=\mathrm{O} / \mathrm{C}-\mathrm{O}-\mathrm{C}$ bonding at $288.2 \mathrm{eV}[13,24,30]$. As compared with the GO powder, the relative intensity of the oxygen-containing bonding of cotton-RGO-AgNP fiber significantly decreases, whereas its relative intensity of oxygen-free bonding apparently increases, once again confirming the in-situ reduction of GO to RGO [24,30]. Additionally, a pair of sharp peaks, corresponding to Ag3d doublets, are available at 374.7 and $368.6 \mathrm{eV}$ in the XPS spectrum of the Ag3d region of cotton-RGO-AgNP fiber with a separation of $6.1 \mathrm{eV}$ (Figure $4 \mathrm{~d}$ ), manifesting the existence of a zero-oxidation state of metallic $\mathrm{Ag}^{0}[24,31,32]$. These XPS signals quite agree with the aforementioned XRD and Raman findings. 


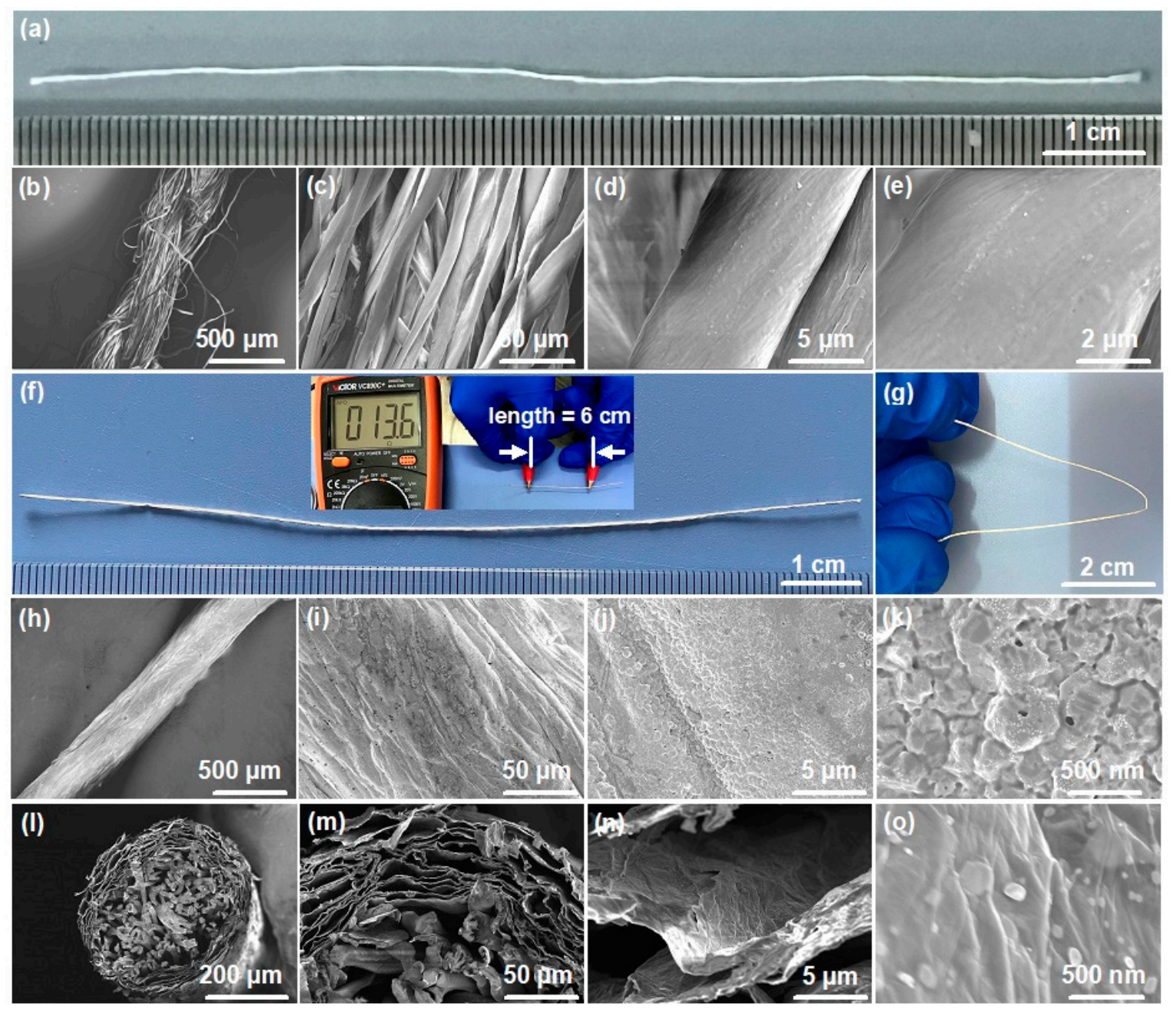

Figure 3. (a) Optical photograph of a length of primary cotton yarn; (b-e) SEM observations of the pure cotton yarn exhibited in (a) at different magnification; ( $\mathbf{f}-\mathbf{g})$ digital images of a length of cotton-RGO-AgNP composite fiber under natural and bent conditions, respectively; the inset of (f) shows the measurement of its electrical resistance using a multimeter; (h-k) top-view SEM inspections of cotton-RGO-AgNP fiber from low to high magnification, displaying morphological details of its outer surface; (1-o) cross-sectional SEM examinations of cotton-RGO-AgNP fiber, which disclose a typical core-shell structure with cotton yarn as core and porous RGO/AgNP composite film as shell.

\subsection{Electrochemical Evaluation}

Thanks to its outstanding conductivity, the naked cotton-RGO-AgNP composite fiber could be directly utilized as a working electrode, and its performances were compared to those of the cotton-RGO fiber electrode under the same conditions. Although they have a similar size in diameter, the area under the $\mathrm{CV}$ curve of the former is much greater than that of the latter (Figure 5a), and the discharge time in the GCD curve of the former is also somewhat longer than that of the latter (Figure 5b), indicating the superior electrochemical properties of the cotton-RGO-AgNP fiber electrode [14,16,24]. We measured the electrical resistance of cottonRGO-AgNP and cotton-RGO fibers, and it was 2.3 and $710 \Omega \mathrm{cm}^{-1}$, respectively. Accordingly, it is assumed that the loaded AgNPs indeed bring about the exceptional conductivity of the cotton-RGO-AgNP fiber electrode, which would sufficiently exert the charge storage ability of the RGO component, leading to its better capacitive behaviors. Figure 6a shows the $\mathrm{CV}$ curves of the cotton-RGO-AgNP fiber electrode at a series of scan rates, where a group of quasi-rectangular curves are available, which are indicative of the typical electrical double-layer capacitive properties $[10,13,33]$. The results of its GCD tests are displayed in Figure $6 \mathrm{~b}$. As can be seen, there are near-linear relationships between the potential and charge/discharge times at varied current densities. In addition, all discharge curves have a 
small IR drop and show acceptable symmetry with their charge counterparts, demonstrating the rapid ion transport and decent reversibility of this fiber electrode [33,34]. Based on the GCD data, the linear specific capacitance $\left(C_{L}\right)$ and volumetric specific capacitance $\left(C_{V}\right)$ are derived and plotted in Figure $6 c$. The rate capability seems to be satisfactory and the largest $C_{L}$ and $C_{V}$ values are acquired at the current density of $0.5 \mathrm{~mA} \cdot \mathrm{cm}^{-1}$, which are ca. $12.09 \mathrm{mF} \cdot \mathrm{cm}^{-1}$ and ca. $9.67 \mathrm{~F} \cdot \mathrm{cm}^{-3}$, respectively (Figure $6 \mathrm{c}$ ). The cyclic performance of such fiber electrodes was surveyed in terms of a continuous GCD test at a current density of $1.25 \mathrm{~mA} \cdot \mathrm{cm}^{-1}$ for up to 10,000 cycles. The results reflect that the capacitance hardly attenuates during the entire measurement (Figure 6d) and the final 10-cycle GCD curve maintains good shape (Figure 6e), testifying to the durable cycling stability. Figure $6 f$ depicts the Nyquist plots of the cotton-RGO-AgNP fiber electrode. As reported in most cases, the Nyquist plots of supercapacitor electrodes mainly consist of a semicircle and an oblique line in high and low frequency regimes, respectively [34,35]. However, an obsolete semicircle is observed for the currently developed fiber electrode, which is likely owing to quite low charge transfer resistance and non-faradaic electrochemical processes, and meanwhile demonstrates high ionic conductivity at the electrode/electrolyte interface [33-35]. The value of the X-intercept refers to equivalent-series resistance, and it is merely $10.7 \Omega$ for the cotton-RGO-AgNP fiber electrode, further suggesting its outstanding electrical conductivity [33-35]. In the low frequency region, the curve is apt to become a slanted line with a big slope. That means electrolyte ions can sufficiently diffuse within the fiber electrode and bring about commendable capacitive properties [33-35]. We also measured the EIS spectrum after the repetitive charge/discharge test, and it shows negligible change as compared to the initial one (Figure 6f), once again confirming the exceptional cyclic performances.
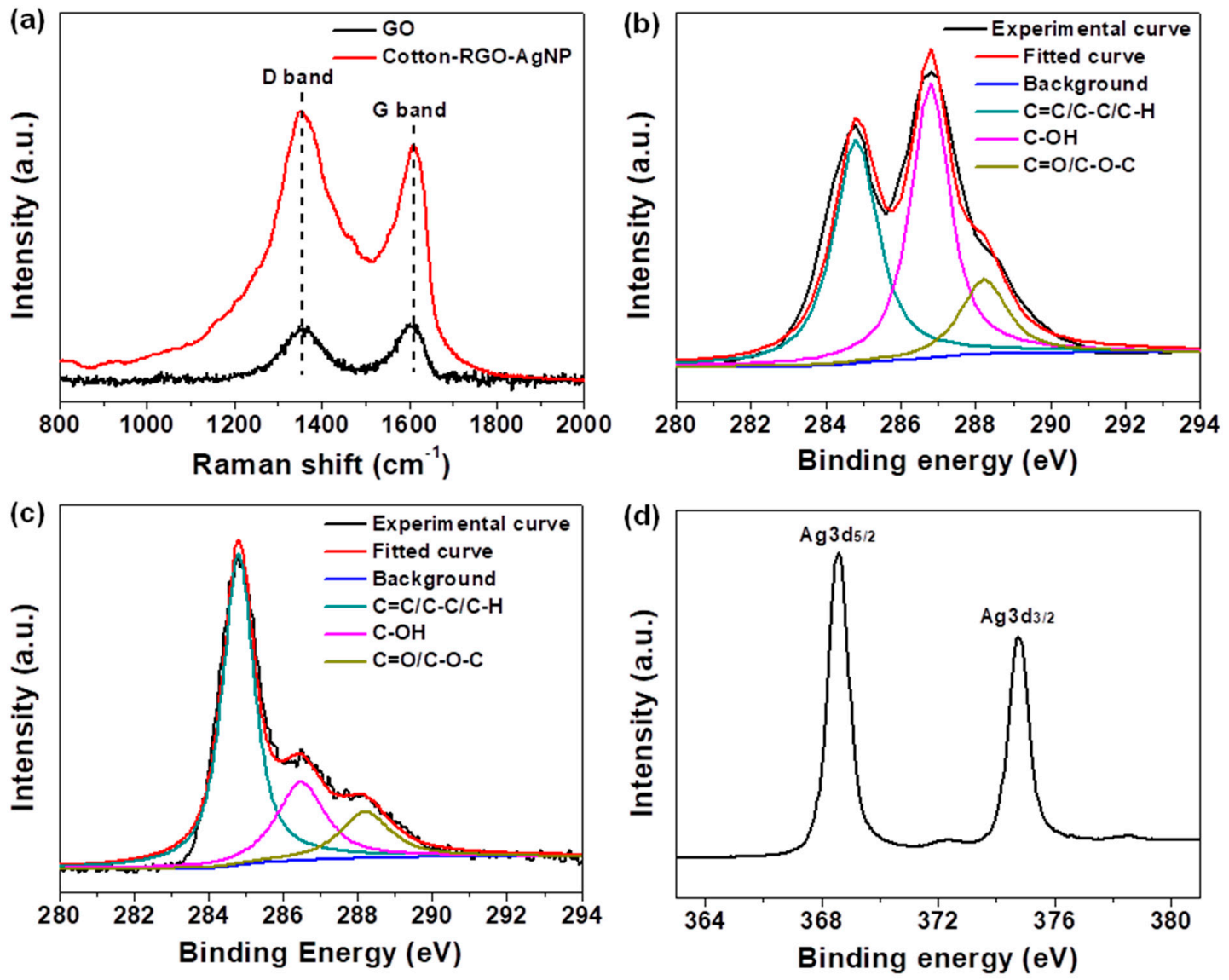

Figure 4. (a) Raman spectra of the purchased GO powder and currently developed cotton-RGO-AgNP fiber, exhibiting obvious D and G bands; (b) high-resolution XPS C1s spectrum of GO powder; (c,d) high-resolution XPS spectra of cotton-RGO-AgNP fiber for the $\mathrm{C} 1 \mathrm{~s}$ and $\mathrm{Ag} 3 \mathrm{~d}$ regions, respectively. 

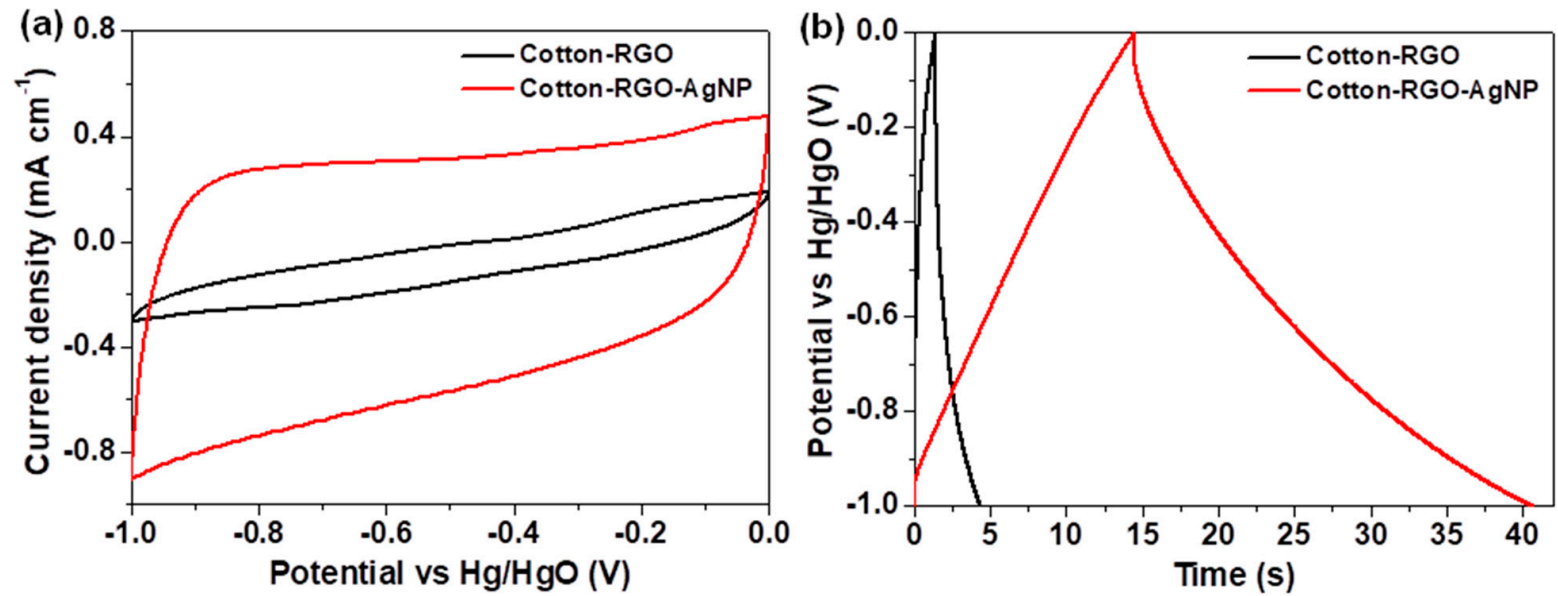

Figure 5. Comparison of electrochemical properties between cotton-RGO and cotton-RGO-AgNP fiber electrodes. (a) The $\mathrm{CV}$ tests conducted at $50 \mathrm{mV} \cdot \mathrm{s}^{-1} ;(\mathbf{b})$ the GCD tests carried out at $0.5 \mathrm{~mA} \cdot \mathrm{cm}^{-1}$.

To better elucidate the electrochemical properties of cotton-RGO-AgNP fiber, it was straight served as anode and cathode to build a parallel symmetric FSSC cell and subjected to the corresponding tests. As envisioned, no conspicuous redox peak is found in the $\mathrm{CV}$ curves and they are all close to a rectangular shape even at the very high scan rate of $500 \mathrm{mV} \cdot \mathrm{s}^{-1}$ (Figure 7a), verifying the characteristic non-faradaic capacitive behaviors and rapid charging/discharging speed of such a device [33-36]. Nevertheless, the GCD curves slightly deviate from a triangular shape with some IR drop (Figure $7 \mathrm{~b}$ ), which probably arises from a certain internal resistance. The specific capacitance of the present FSSC cell is calculated as well. By boosting the current density from 0.2 to $2 \mathrm{~mA} \cdot \mathrm{cm}^{-1}$, its $C_{\mathrm{L}}$, FSSC values descend from ca. 1.67 to ca. $0.44 \mathrm{mF} \cdot \mathrm{cm}^{-1}$ and its $C_{\mathrm{V}}$, FSSC values decrease from ca. 0.67 to ca. $0.17 \mathrm{~F} \cdot \mathrm{cm}^{-3}$ (Figure $7 \mathrm{c}$ ). Although the rate capability seems to be not fully desirable, its cyclic durability is fairly superior to that of plenty of recently developed textile yarn- and graphene-based FSSC devices [14,17-20,30,37], as no obvious capacitance deterioration is monitored during the whole cycling stability test and the last 10-cycle charge/discharge curve remains intact as well (Figure 7d). Flexibility is of great importance for the real applications of FSSC devices and such a property is often evaluated by bending tests. Clearly, almost overlapping CV and GCD curves are gained by easily bending the FSSC cell of cotton-RGO-AgNP/ / cotton-RGO-AgNP at different angles (Figure 7e,f), demonstrating the highly stable electrochemical and mechanical performances. The insets of Figure 8a show the digital photos of our FSSC cell under normal and bent states, whose Ragone plots are also visually profiled in Figure 8a. It delivers the highest power density of $555.6 \mu \mathrm{W} \cdot \mathrm{cm}^{-3}$ at an energy density of ca. $23.6 \mu \mathrm{Wh} \cdot \mathrm{cm}^{-3}$ and offers the maximum energy density of ca. $93.1 \mu \mathrm{Wh} \cdot \mathrm{cm}^{-3}$ at a power density of $40.7 \mu \mathrm{W} \cdot \mathrm{cm}^{-3}$, which rivals or even surpasses that of a number of previously developed FSSCs $[17,19,28,37-40]$, exhibiting noticeable charge storage advantages. Moreover, to explore the realistic feasibility and application potential, three units of the currently fabricated FSSC were linked in series and then completely charged as a power supply. It can be seen that a red LED bulb immediately sparkles with dazzling light upon being linked to this tandem device. Such a phenomenon once again reveals the large power density and fast discharge ability of our FSSC. 

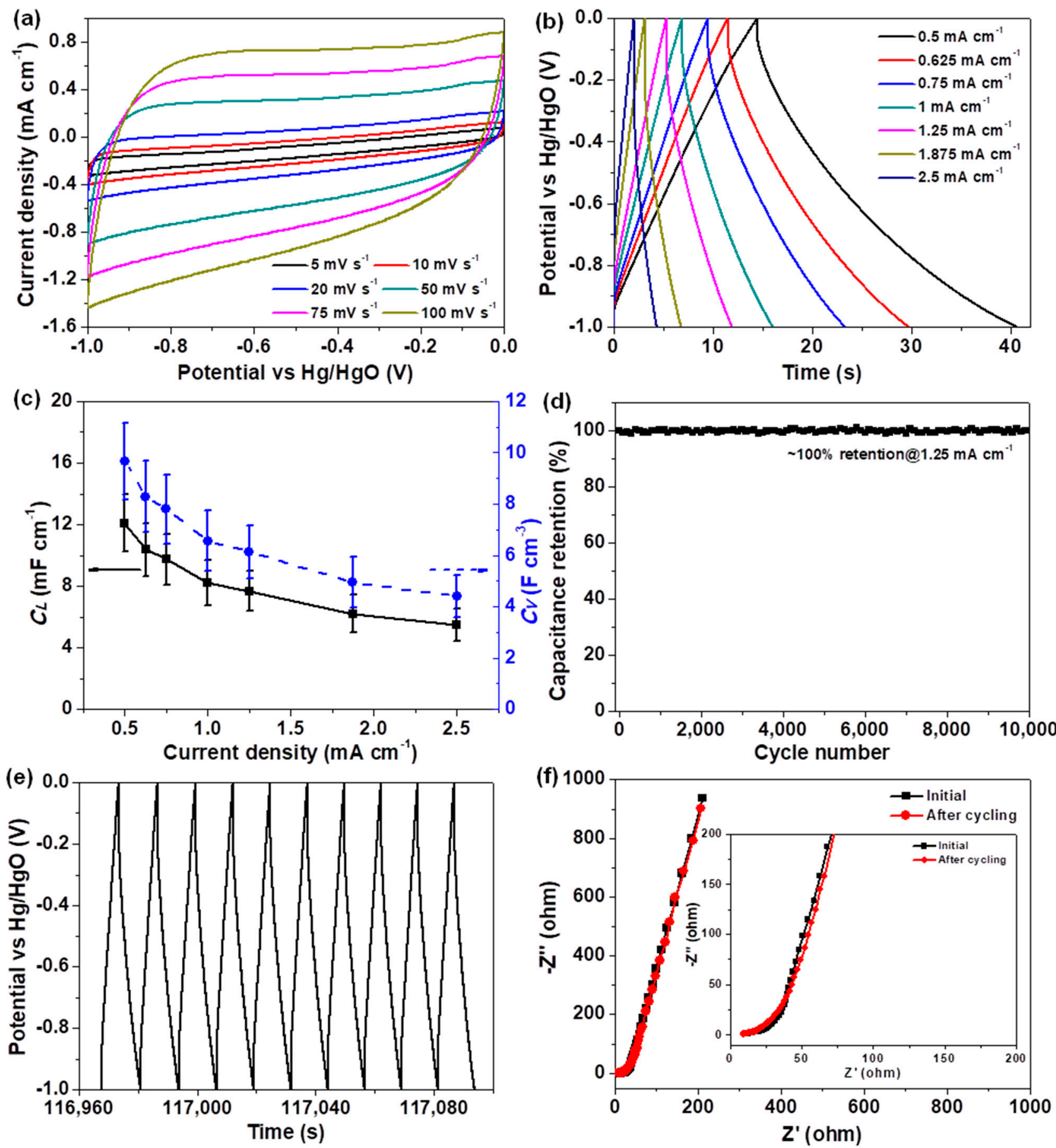

Figure 6. Electrochemical performances of cotton-RGO-AgNP fiber electrode characterized in three-electrode system. (a) Its CV curves measured in the range of $5-100 \mathrm{mV} \cdot \mathrm{s}^{-1}$. (b) Its GCD curves measured in the range of $0.5-2.5 \mathrm{~mA} \cdot \mathrm{cm}{ }^{-1}$. (c) Plot of its linear $\left(C_{L}\right)$ and volumetric $\left(C_{V}\right)$ specific capacitance vs. current density. (d) Cyclic performance of this fiber electrode. (e) The final 10-cycle GCD curve for the cycling durability test. (f) Its initial and post-cycling Nyquist plots with zoomed views of the high-frequency regimes given in the inset. 
(a) 1.2

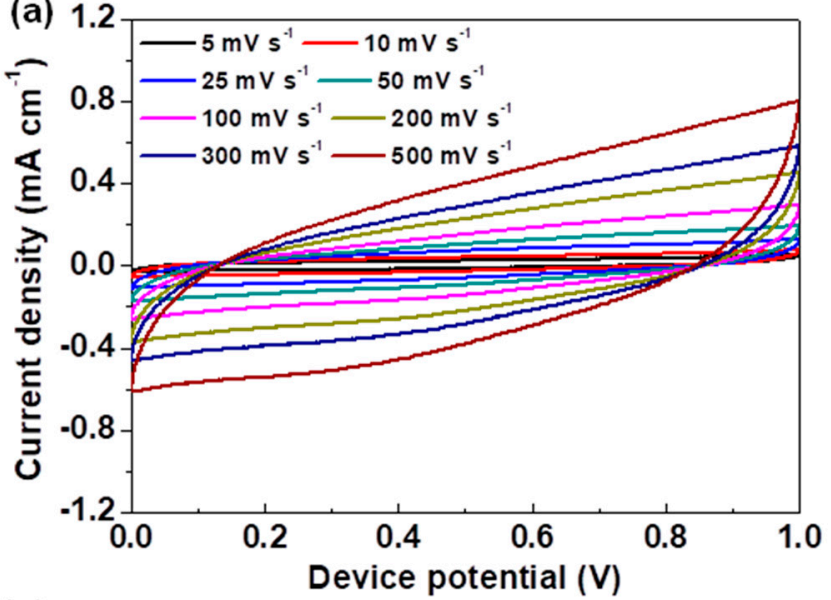

(c)

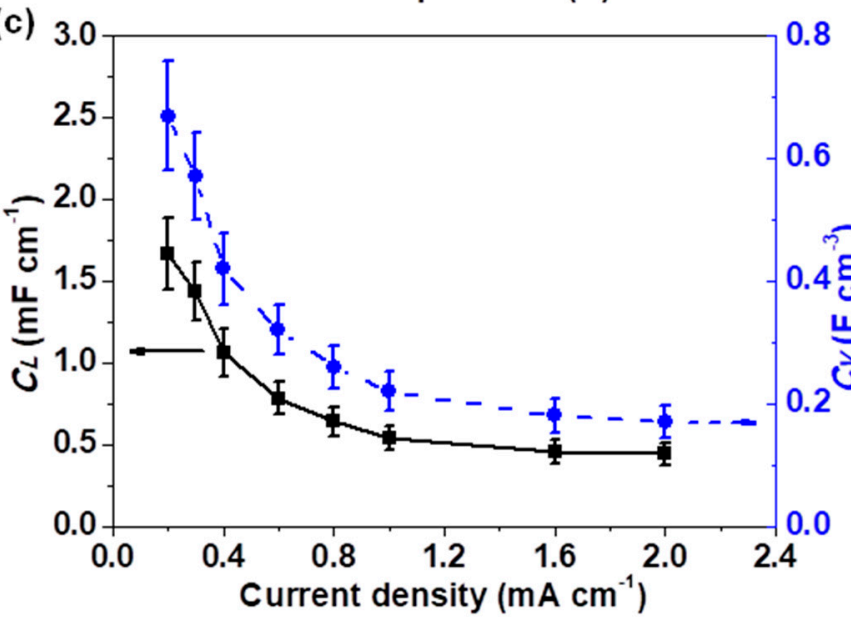

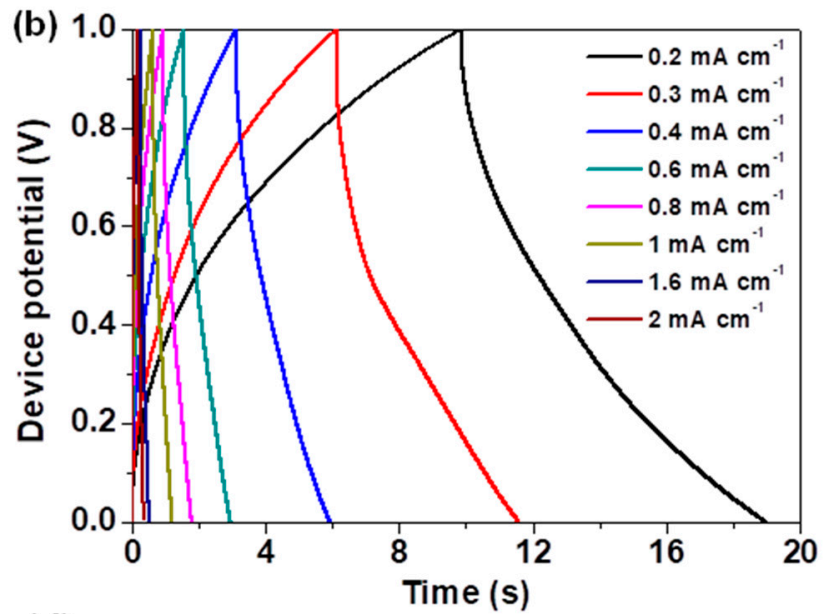

(d)

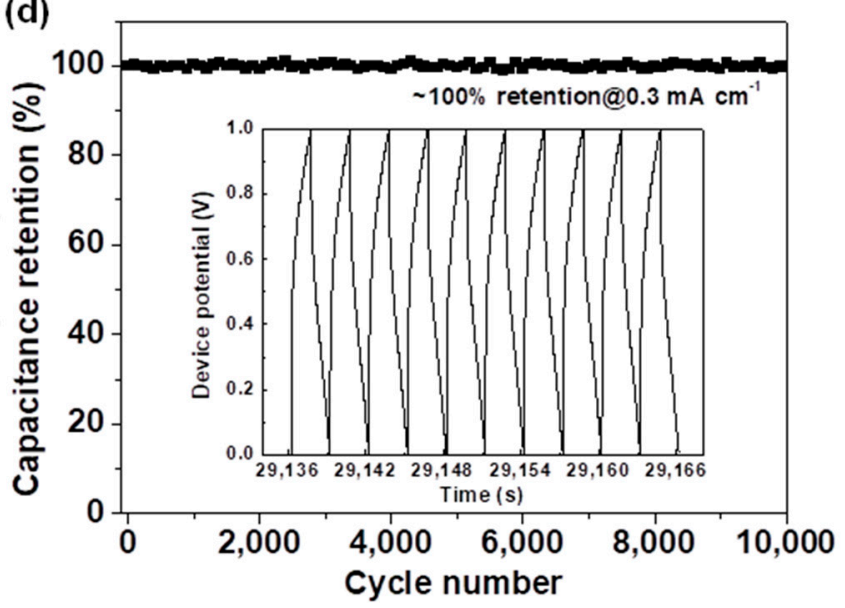

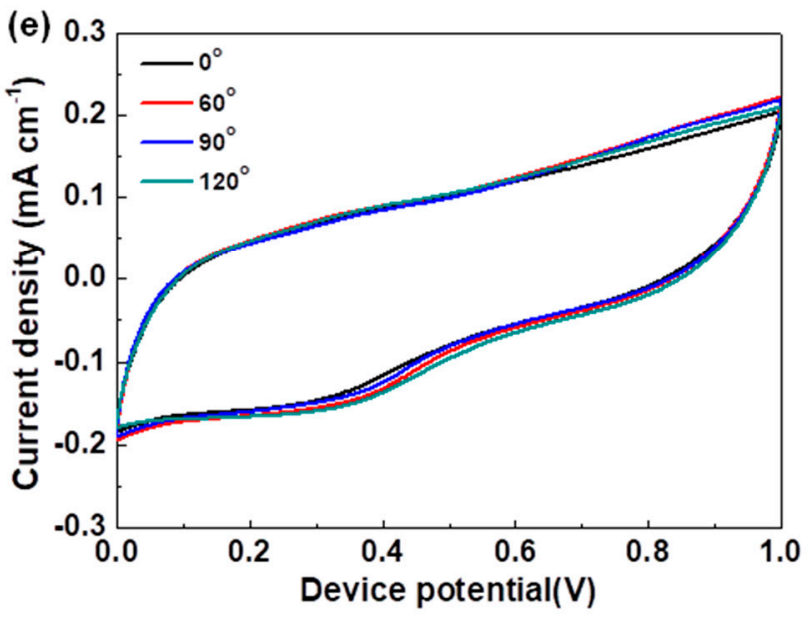

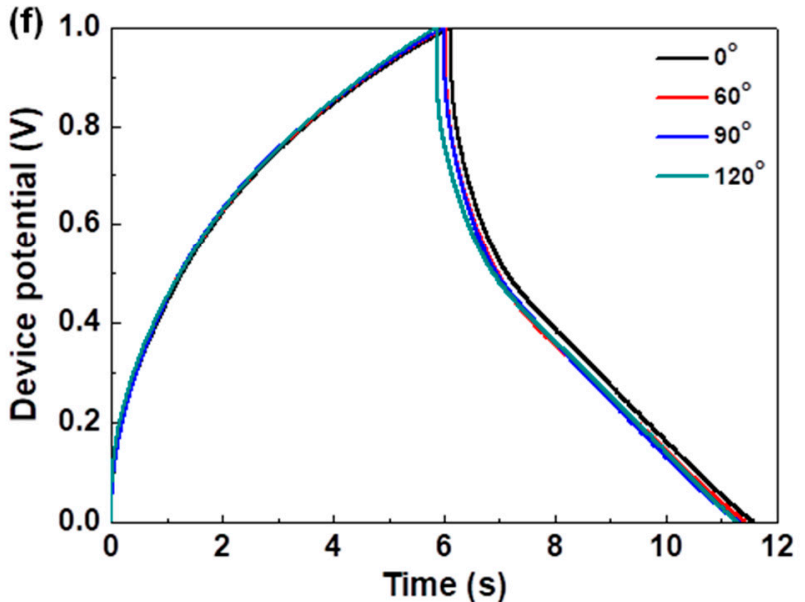

Figure 7. Capacitive properties of the currently developed parallel symmetric FSSC cell (i.e., cotton-RGO-AgNP// cottonRGO-AgNP). (a,b) CV and GCD curves recorded at varied scan rates and current densities, respectively; (c) plot of the relationship between specific capacitance and current density; (d) cyclic performance of such an FSSC cell; the inset presents the last 10-cycle GCD curve for the cycling durability investigation; $(\mathbf{e}, \mathbf{f})$ performances of bending tests evaluated by $\mathrm{CV}$ measurements at $100 \mathrm{mV} \cdot \mathrm{s}^{-1}$ and GCD measurements at $0.3 \mathrm{~mA} \cdot \mathrm{cm}^{-1}$ under different bent states, respectively. 


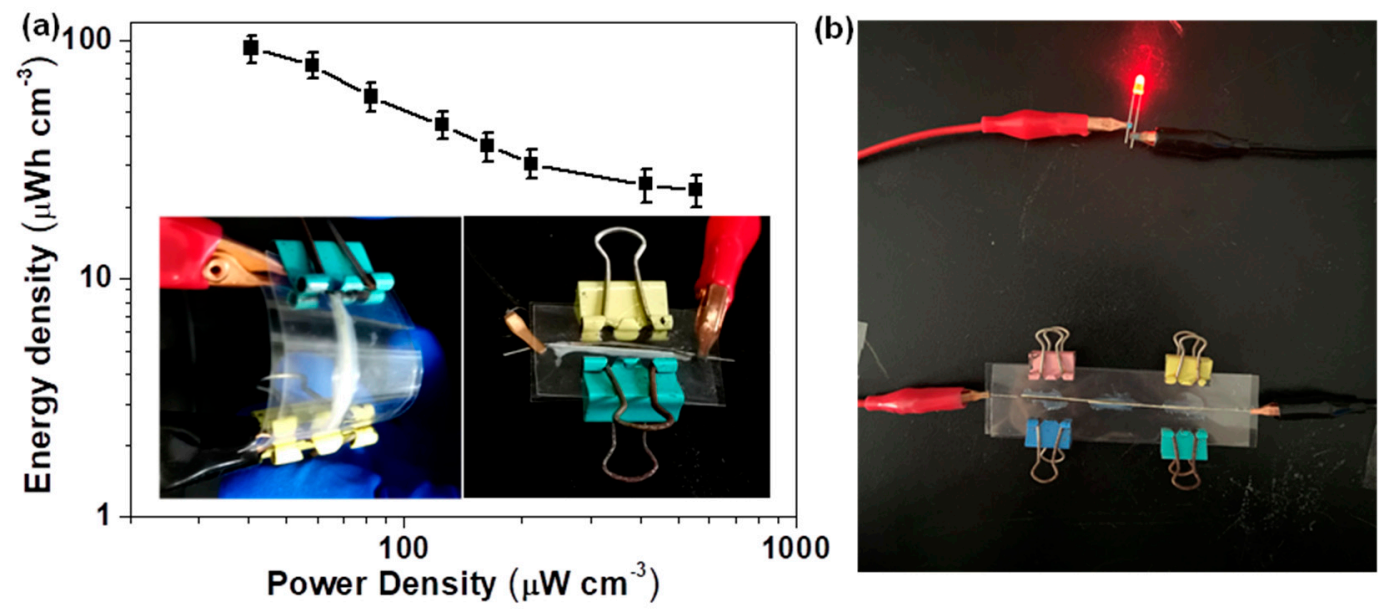

Figure 8. (a) Ragone plot of the currently developed FSSC cell and its optical pictures under natural and curved conditions; (b) optical image of a glittering LED bead well driven by three serial-connected FSSC cells.

\section{Conclusions}

In conclusion, a core-shell-structured cotton-RGO-AgNP composite fiber was prepared by coating cotton yarn with a GO layer followed by the electrostatic adsorption of a silver-ammonia complex and chemical reduction in hydrazine vapor. On account of the distinct morphology and extraordinary electrical conductivity, it was employed as a fiber-shaped working electrode in a three-electrode system and gave the highest linear specific capacitance of ca. $12.09 \mathrm{mF} \cdot \mathrm{cm}^{-1}$ (corresponding to a volumetric specific capacitance of ca. $9.67 \mathrm{~F} \cdot \mathrm{cm}^{-3}$ ) with a desirable rate capability and cyclic performance. Later, a symmetric parallel FSSC cell of cotton-RGO-AgNP//cotton-RGO-AgNP was further developed, which had a maximum linear specific capacitance as high as ca. $1.67 \mathrm{mF} \cdot \mathrm{cm}^{-1}$ (corresponding to a volumetric specific of ca. $0.67 \mathrm{~F} \cdot \mathrm{cm}^{-3}$ ). It released the largest energy density of up to ca. $93.1 \mu \mathrm{Wh} \mathrm{cm} \mathrm{cm}^{-3}$ and showed long-term cycling durability together with an interesting application potential and stable capacitive behaviors under various curved states. As a consequence, the present research work affords helpful insights into the design and preparation of textile yarn-based electrodes and FSSC devices, which would advance their developments in many cutting-edge fields, such as smart wearable electronics and flexible energy storage.

Author Contributions: Conceptualization, W.X. and Y.D.; methodology, W.Z. and Q.J.; investigation, W.X. and J.H.; writing-original draft preparation, W.X. and L.T.; writing-review and editing, Y.Z. and Y.D.; supervision, Y.D.; project administration, Y.Z.; funding acquisition, Y.D. All authors have read and agreed to the published version of the manuscript.

Funding: This research was funded by the Science and Technology Research Program of Chongqing Municipal Education Commission (Grant Nos. KJQN202001304 and KJZD-K202001305), the Chongqing Research Program of Basic Research and Frontier Technology (Grant Nos. cstc2017jcyjBX0051 and cstc2018jcyjAX0212), Natural Science Foundation of Chongqing (Grant No. cstc2020jcyj-msxmX0103) and the Fund for Creative Research Group of Micro-Nano Semiconductor and Photonic Materials of Chongqing Municipal Education Commission and the APC was funded by the Foundation of Chongqing University of Arts and Sciences (Grant No. P2020CL02).

Institutional Review Board Statement: Not applicable.

Informed Consent Statement: Not applicable.

Data Availability Statement: Not applicable.

Acknowledgments: The authors sincerely thank Zhanghua Zou, from Chongqing University of Arts and Sciences, for the SEM inspections on the corresponding specimens.

Conflicts of Interest: The authors declare no conflict of interest. 


\section{References}

1. Chen, D.; Jiang, K.; Huang, T.; Shen, G. Recent advances in fiber supercapacitors: Materials, device configurations, and applications. Adv. Mater. 2020, 32, 1901806. [CrossRef]

2. Zhai, S.; Karahan, H.E.; Wang, C.; Pei, Z.; Wei, L.; Chen, Y. 1D supercapacitors for emerging electronics: Current status and future directions. Adv. Mater. 2020, 32, 1902387. [CrossRef]

3. Zhou, Y.; Wang, C.-H.; Lu, W.; Dai, L. Recent advances in fiber-shaped supercapacitors and lithium-ion batteries. Adv. Mater. 2020, 32, 1902779. [CrossRef] [PubMed]

4. Keum, K.; Lee, G.; Lee, H.; Yun, J.; Park, H.; Hong, S.Y.; Song, C.; Kim, J.W.; Ha, J.S. Wire-shaped supercapacitor with organic electrolyte fabricated via layer-by-layer assembly. ACS Appl. Mater. Interfaces 2018, 10, 26248-26257. [CrossRef] [PubMed]

5. Gao, L.; Song, J.; Surjadi, J.U.; Cao, K.; Han, Y.; Sun, D.; Tao, X.-M.; Lu, Y. Graphene-bridged multifunctional flexible fiber supercapacitor with high energy density. ACS Appl. Mater. Interfaces 2018, 10, 28597-28607. [CrossRef] [PubMed]

6. Zhou, C.; Gao, T.; Liu, Q.; Wang, Y.; Xiao, D. Preparation of quinone modified graphene-based fiber electrodes and its application in flexible asymmetrical supercapacitor. Electrochim. Acta 2020, 336, 135628. [CrossRef]

7. Shahrokhian, S.; Naderi, L.; Mohammadi, R. High-performance fiber-shaped flexible asymmetric micro-supercapacitor based on $\mathrm{Ni}(\mathrm{OH})_{2}$ nanoparticles-decorated porous dendritic $\mathrm{Ni}-\mathrm{Cu}$ wire and reduced graphene oxide/carbon fiber electrodes. ACS Sustain. Chem. Eng. 2018, 6, 14574-14588. [CrossRef]

8. Ruan, D.; Lin, R.; Jiang, K.; Yu, X.; Zhu, Y.; Fu, Y.; Wang, Z.; Yan, H.; Mai, W. High-performance porous molybdenum oxynitride based fiber supercapacitors. ACS Appl. Mater. Interfaces 2017, 9, 29699-29706. [CrossRef]

9. Meng, J.; Nie, W.; Zhang, K.; Xu, F.; Ding, X.; Wang, S.; Qiu, Y. Enhancing electrochemical performance of graphene fiber-based supercapacitors by plasma treatment. ACS Appl. Mater. Interfaces 2018, 10, 13652-13659. [CrossRef] [PubMed]

10. Ma, W.; Li, M.; Zhou, X.; Li, J.; Dong, Y.; Zhu, M. Three-dimensional porous carbon nanotubes/reduced graphene oxide fiber from rapid phase separation for a high-rate all-solid-state supercapacitor. ACS Appl. Mater. Interfaces 2019, 11, 9283-9290. [CrossRef]

11. Lu, M.; Zhang, Z.; Kang, L.; He, X.; Li, Q.; Sun, J.; Jiang, R.; Xu, H.; Shi, F.; Lei, Z.; et al. Intercalation and delamination behaviour of $\mathrm{Ti}_{3} \mathrm{C}_{2} \mathrm{~T}_{x}$ and $\mathrm{MnO}_{2} / \mathrm{Ti}_{3} \mathrm{C}_{2} \mathrm{~T}_{x} / \mathrm{RGO}$ flexible fiber with high volumetric capacitance. J. Mater. Chem. A 2019, 7, 12582-12592. [CrossRef]

12. Sasikala, S.P.; Lee, K.E.; Lim, J.; Lee, H.J.; Koo, S.H.; Kim, I.H.; Jung, H.J.; Kim, S.O. Interface-confined high crystalline growth of semiconducting polymers at graphene fibers for high-performance wearable supercapacitors. ACS Nano 2017, 11, 9424-9434 [CrossRef]

13. Guan, T.; Shen, L.; Bao, N. Hydrophilicity improvement of graphene fibers for high-performance flexible supercapacitor. Ind. Eng. Chem. Res. 2019, 58, 17338-17345. [CrossRef]

14. Wang, H.-T.; Liu, Y.-N.; Kang, X.-H.; Wang, Y.-F.; Yang, S.-Y.; Bian, S.-W.; Zhu, Q. Flexible hybrid yarn-shaped supercapacitors based on porous nickel cobalt sulphide nanosheet array layers on gold metalized cotton yarns. J. Colloid Interface Sci. 2018, 532, 527-535. [CrossRef] [PubMed]

15. Wang, H.-T.; Jin, C.; Liu, Y.-N.; Kang, X.-H.; Bian, S.-W.; Zhu, Q. Cotton yarns modified with three-dimensional metallic Ni conductive network and pseudocapacitive Co-Ni layered double hydroxide nanosheet array as electrode materials for flexible yarn supercapacitors. Electrochim. Acta 2018, 283, 1789-1797. [CrossRef]

16. Jin, C.; Wang, H.-T.; Liu, Y.-N.; Kang, X.-H.; Liu, P.; Zhang, J.-N.; Jin, L.-N.; Bian, S.-W.; Zhu, Q. High-performance yarn electrode materials enhanced by surface modifications of cotton fibers with graphene sheets and polyaniline nanowire arrays for all-solid-state supercapacitors. Electrochim. Acta 2018, 270, 205-214. [CrossRef]

17. Lima, R.M.A.P.; Alcaraz-Espinoza, J.J.; da Silva , F.A.G., Jr.; de Oliveira, H.P. Multifunctional wearable electronic textiles using cotton fibers with polypyrrole and carbon nanotubes. ACS Appl. Mater. Interfaces 2018, 10, 13783-13795. [CrossRef]

18. Das, C.; Krishnamoorthy, K. Flexible micro-supercapacitors using silk and cotton substrates. ACS Appl. Mater. Interfaces 2016, 8 , 29504-29510. [CrossRef] [PubMed]

19. Zhou, Q.; Jia, C.; Ye, X.; Tang, Z.; Wan, Z. A knittable fiber-shaped supercapacitor based on natural cotton thread for wearable electronics. J. Power Sources 2016, 327, 365-373. [CrossRef]

20. Liu, N.; Ma, W.; Tao, J.; Zhang, X.; Su, J.; Li, L.; Yang, C.; Gao, Y.; Golberg, D.; Bando, Y. Cable-type supercapacitors of threedimensional cotton thread based multi-grade nanostructures for wearable energy storage. Adv. Mater. 2013, 25, 4925-4931. [CrossRef]

21. Liu, L.; Yu, Y.; Yan, C.; Li, K.; Zheng, Z. Wearable energy-dense and power-dense supercapacitor yarns enabled by scalable graphene-metallic textile composite electrodes. Nat. Commun. 2015, 6, 7260. [CrossRef]

22. Ahmad, I.; Kan, C.-w.; Yao, Z. Photoactive cotton fabric for UV protection and self-cleaning. RSC Adv. 2019, 9, 18106-18114. [CrossRef]

23. Qu, J.; Qian, J.; Wu, M.; Mao, Q.; Li, M. Hydrothermal synthesis of cotton-based $\mathrm{BiVO}_{4} / \mathrm{Ag}$ composite for photocatalytic degradation of C.I. Reactive Black 5. RSC Adv. 2020, 10, 39295-39303. [CrossRef]

24. Zou, Z.; Xiao, W.; Zhang, Y.; Yu, H.; Zhou, W. Facile synthesis of freestanding cellulose/RGO/silver $/ \mathrm{Fe}_{2} \mathrm{O}_{3}$ hybrid film for ultrahigh-areal-energy-density flexible solid-state supercapacitor. Appl. Surf. Sci. 2020, 500, 144244. [CrossRef]

25. Xiao, W.; Zhou, W.; Zhang, Y.; Tian, L.; Liu, H.; Pu, Y. Three-dimensional $\mathrm{Zn}_{0.5} \mathrm{Cd}_{0.5} \mathrm{~S} /$ reduced graphene oxide hybrid aerogel: Facile synthesis and the visible-light-driven photocatalytic property for reduction of Cr(VI) in water. J. Nanomater. 2016, 2016, 6201546. [CrossRef] 
26. Han, W.; Ren, L.; Gong, L.; Qi, X.; Liu, Y.; Yang, L.; Wei, X.; Zhong, J. Self-assembled three-dimensional graphene-based aerogel with embedded multifarious functional nanoparticles and its excellent photoelectrochemical activities. ACS Sustain. Chem. Eng. 2014, 2, 741-748. [CrossRef]

27. Smith, R.E.; Totti, S.; Velliou, E.; Campagnolo, P.; Hingley-Wilson, S.M.; Ward, N.I.; Varcoe, J.R.; Crean, C. Development of a novel highly conductive and flexible cotton yarn for wearable $\mathrm{pH}$ sensor technology. Sens. Actuators B Chem. 2019, 287, 338-345. [CrossRef]

28. Fu, Y.; Cai, X.; Wu, H.; Lv, Z.; Hou, S.; Peng, M.; Yu, X.; Zou, D. Fiber supercapacitors utilizing pen ink for flexible/wearable energy storage. Adv. Mater. 2012, 24, 5713-5718. [CrossRef] [PubMed]

29. Yang, M.; Fu, C.; Xia, Z.; Cheng, D.; Cai, G.; Tang, B.; Wang, X. Conductive and durable CNT-cotton ring spun yarns. Cellulose 2018, 25, 4239-4249. [CrossRef]

30. Zhang, Z.; Zhang, D.; Lin, H.; Chen, Y. Flexible fiber-shaped supercapacitors with high energy density based on self-twisted graphene fibers. J. Power Sources 2019, 433, 226711. [CrossRef]

31. Suresh, S.; Unni, G.E.; Satyanarayana, M.; Nair, A.S.; Pillai, V.P.M. Ag@ $\mathrm{Nb}_{2} \mathrm{O}_{5}$ plasmonic blocking layer for higher efficiency dye-sensitized solar cells. Dalton Trans. 2018, 47, 4685-4700. [CrossRef] [PubMed]

32. Chen, L.; Deming, C.P.; Peng, Y.; Hu, P.; Stofan, J.; Chen, S. Gold core@silver semishell Janus nanoparticles prepared by interfacial etching. Nanoscale 2016, 8, 14565-14572. [CrossRef]

33. Lu, C.; Meng, J.; Zhang, J.; Chen, X.; Du, M.; Chen, Y.; Hou, C.; Wang, J.; Ju, A.; Wang, X.; et al. Three-dimensional hierarchically porous graphene fiber-shaped supercapacitors with high specific capacitance and rate capability. ACS Appl. Mater. Interfaces 2019, 11, 25205-25217. [CrossRef] [PubMed]

34. Zou, Z.; Zhou, W.; Zhang, Y.; Yu, H.; Hu, C.; Xiao, W. High-performance flexible all-solid-state supercapacitor constructed by free-standing cellulose/reduced graphene oxide/silver nanoparticles composite film. Chem. Eng. J. 2019, 357, 45-55. [CrossRef]

35. Zheng, Q.; Cai, Z.; Ma, Z.; Gong, S. Cellulose nanofibril/reduced graphene oxide/carbon nanotube nanotube hybrid aerogels for highly flexible and all-solid-state supercapacitors. ACS Appl. Mater. Interfaces 2015, 7, 3263-3271. [CrossRef]

36. Chen, G.; Chen, T.; Hou, K.; Ma, W.; Tebyetekerwa, M.; Cheng, Y.; Weng, W.; Zhu, M. Robust, hydrophilic graphene/cellulose nanocrystal fiber-based electrode with high capacitive performance and conductivity. Carbon 2018, 127, 218-227. [CrossRef]

37. Ye, X.; Zhou, Q.; Jia, C.; Tang, Z.; Wan, Z.; Wu, X. A Knittable fibriform supercapacitor based on natural cotton thread coated with graphene and carbon nanoparticles. Electrochim. Acta 2016, 206, 155-164. [CrossRef]

38. Yu, J.; Wang, M.; Xu, P.; Cho, S.-H.; Suhr, J.; Gong, K.; Meng, L.; Huang, Y.; Byun, J.-H.; Oh, Y.; et al. Ultrahigh-rate wire-shaped supercapacitor based on graphene fiber. Carbon 2017, 119, 332-338. [CrossRef]

39. Le, V.T.; Kim, H.; Ghosh, A.; Kim, J.; Chang, J.; Vu, Q.A.; Pham, D.T.; Lee, J.-H.; Kim, S.-W.; Lee, Y.H. Coaxial fiber supercapacitor using all-carbon material electrodes. ACS Nano 2013, 7, 5940-5947. [CrossRef]

40. Yang, P.; Xiao, X.; Li, Y.; Ding, Y.; Qiang, P.; Tan, X.; Mai, W.; Lin, Z.; Wu, W.; Li, T.; et al. Hydrogenated ZnO core-shell nanocables for flexible supercapacitors and self-powered system. ACS Nano 2013, 7, 2617-2626. [CrossRef] 